Alan Mossman (2018). "What is lean construction: another look." In: Proc. $26^{\text {th }}$ Annual Conference of the International. Group for Lean Construction (IGLC), González, V.A. (ed.), Chennai, India, pp. 1240-1250. DOI: doi.org/10.24928/2018/0309. Available at: www.iglc.net

\title{
WHAT IS LEAN CONSTRUCTION: ANOTHER LOOK - 2018
}

\begin{abstract}
Alan Mossman ${ }^{1}$
ABSTRACT

There is no agreed definition of lean construction. This is a problem for some and not for others in the lean construction community and beyond.

Answers to the question "what is lean construction?" from a simple survey reported here, on the web and in the formal and informal literature reveal a diversity of views. The purpose of the survey was to get a sense of the definitions-in-use in the lean construction community.

Some of the implications for the community are outlined and suggestions made for further study.
\end{abstract}

\section{KEYWORDS}

lean construction, lean, definition,

\section{INTRODUCTION}

"there is no universal accepted, explicit definition of lean construction

Dauber 2003: 29

"a multifaceted concept that defies universal definition Green and May 2005

"Various parties within construction ... have different explanations of what lean construction means. There are inconsistent definitions and little agreement among practitioners.

Leong et al 2015

"Lean does not have an agreed definition, it has numerous, ..., this is the subject of discussions between academics, and professionals. Not having a specific definition has not stopped Lean from being successfully applied in motor manufacturing ".

O’Neil 2016

The first problem in introducing Lean Construction in Japan is that its definition is not clear.

Inokuma 2017

Some suggest there should not be a definition. Others argue that there should. The stimulus for this paper was reading this definition in a recent $\mathrm{PhD}$ thesis:

"A combination of original research and practical development in design and construction with an adoption of lean manufacturing principles and practices (i.e.,

1 Director, The Change Business Ltd, 19 Piccadilly, Stroud, GL5 1HB, UK; +44 7968485 627; alanmossman@mac.com 
Toyota Management System) to the end-to-end design and construction process.

Lean construction is concerned with the alignment and holistic pursuit of concurrent and continuous improvements in all dimensions of the built and natural environment: design, construction, activation, maintenance, salvaging and recycling. Austin 2016

Even though the literature is littered with definitions, I looked in vain in the $\mathrm{PhD}$ for sources for this definition (this study has shown the first sentence is virtually identical to the one offered by Wikipedia, the second draws heavily on part of the AGC definition).

\section{WHAT IS A DEFINITION?}

"An exact statement or description of the nature, scope, or meaning of something" Oxford English Dictionary [from Latin definitio(n-), from the verb definire 'set bounds to'].

This raises questions about what is meant by nature, scope and meaning. There is not space here to discuss that.

An operational definition defines the subject of the definition in such a way that it can be measured (Deming 1985; 1994, 150). As Leong et al (2015) note: 'An operational definition puts communicable meaning into a concept. ... lean thinking \& lean construction are concepts and there is a great deal of confusion in industry regarding these concepts.'

\section{WHAT ARE THE CRITERIA FOR A GOOD DEFINITION?}

Greg Howell's criterion for a successful definition of lean construction (that practitioners of traditional construction should not be able to assert "we do that" and be able to ground their assertion) is an example of a simple yes/no metric (Howell, personal email).It is very, very difficult to learn when you already know (or just think you know). Common retorts to attempts to define or explain Lean Construction begins with:

\section{"Oh, we do that already"; \\ "there's nothing new here, it's all common sense",}

Both comments indicate that the individual has decided that there is nothing new to learn and illustrate why Howell's criterion is so important.

A definition of lean construction could reasonably be expected to:

- differentiate - and therefore exclude those who practice traditionally

- be operational - in Deming's sense

- be concise - as simple as possible and no simpler as Einstein may have said

- reduce communication difficulties (Dale \& Plunkett 1991 in Boaden, 1997 quoted by Petttersen 2009).

- simplify education on the subject (Boaden 1997 quoted by Petttersen 2009).

- make research easier (Godfrey et al 1997; Parker 2003) - although Boaden (1997) states that this is not essential(all quoted by Petttersen 2009) ${ }^{2}$.

\footnotetext{
${ }^{2}$ This and the previous criterion begs the question "what is the definition of traditional construction?"
} 
- make it easier to define overall goals of the concept (Andersson et al, 2006 quoted by Petttersen 2009).

\section{BUT/AND}

If, as I believe, one of the presuppositions about lean and lean construction is that "nothing is so good that it cannot be made better" any definition can be improved. As Bertelsen notes (see below) our understanding has changed and continues to change.

Howard Ashcraft wrote (email):I think that you need at least 2 definitions. One to illustrate how Lean differs from traditional practice (gatekeeper definition) and one that illuminates its essence (philosophical definition).

\section{ADVANTAGES OF A DEFINITION OF LEAN CONSTRUCTION}

- To increase the chances that researchers and writers are researching \& writing about the same topic (c.f. Green \& May 2005, Green 2011; see Mossman 2012)

- Green (2011) suggests it will increase chances that lean construction will consistently live up to the claims made for it- [I'm not sure how that works]

- make it easier to evaluate its application and its effectiveness (Leong et al 2015)

- remove an obstacle to adoption by contractors (Gao and Low, 2013; Stevens, 2014).

\section{ADVANTAGES OF NO LEAN CONSTRUCTION DEFINITION}

I feel the lean construction community is similar to a religious community. If that is true:

- reduces potential for bitter rivalries and schism arising from defining' one true way'

- the different images of lean construction implicit in the variety of definitions that already exist offer a richer set of ideas and possibilities, than one single view could.

\section{A SELECT CHRONOLOGY OF DEFINITIONS}

The term lean construction appears to have been coined in 1993 in time for the first IGLC meeting.

At IGLC in 1999, Howell presented "What is lean construction" concluding: Lean construction results from the application of a new form of production management to construction. Essential features of lean construction include a clear set of objectives for the delivery process, aimed at maximizing performance for the customer at the project level, concurrent design of product and process, and the application of production control throughout the life of the product from design to delivery.

In 2002 Lauri Koskela, Greg Howell, Glenn Ballard \& Iris Tommelein (p.211) defined it as "A way to design production systems to minimize waste of materials, time, and effort in order to generate the maximum possible amount of value."

At the $12^{\text {th }}$ IGLC in 2004 Luis Alarçon is reported to have said "We started the discussion about what we mean by lean construction in 1993 in Espoo, a discussion we have had since then. And we still do." [personal email from Sven Bertelsen in 2010] 
In a CII report, Diekmanet al (2004) wrote "the continuous process of eliminating waste, meeting or exceeding all customer requirements, focusing on the entire value stream, and pursuing perfection in the execution of a constructed project."

In 2005 there was a discussion in the IGLC yahoo group "Should we answer the question "What is lean construction?"?"

Both Court 2009 and Sayer \& Anderson 2012 quote LCI's definition: "a production management based approach to project delivery, a new way to design and build capital facilities.(c.f. later LCI definition below)

In LCI's Transforming Design \& Construction- a framework for change (Seed 2010) the five-page chapter titled "Lean construction defined" offers: a respect- and relationship-oriented production management-based approach to project delivery-a new and transformational way to design and build capital facilities.

By 2012, in presentations, Glen Ballard was using "An application to construction of a management philosophy defined by the ideal it pursues,the principles followed in pursuit of the ideal, and the methods used to implement the principles." Greg Howell was using this same wording by 2013.Ballard continues to use that form of words (e.g. at the Dec 2017Lean in the Public Sector meeting). In a 2012 IGLC paper Ballard defined what he understands the words in bold to mean.

At IGLC in 2012 Pekuriet al reported “... it is still difficult to define exactly what the term "lean construction" means."

Abdelhamid's website (2013) includes"A holistic facility design \& delivery philosophy with an overarching aim of maximizing value to all stakeholders through systematic, synergistic \& continuous improvements in contractual arrangements, product design, construction process design \& methods selection, the supply chain and the workflow reliability of site operations."https://msu.edu/user/tariq/Learn_Lean.html 19nov17 


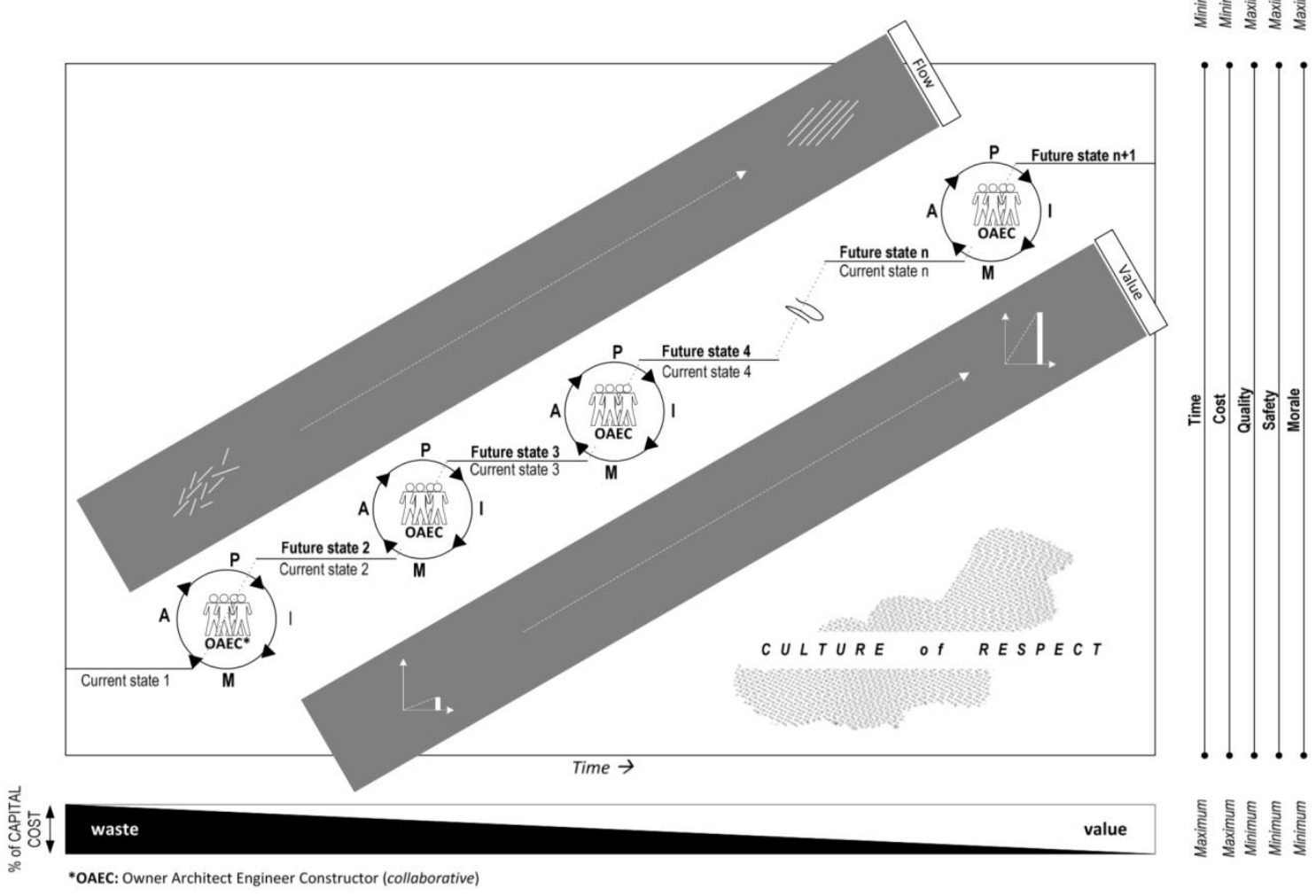

Figure 1: The "who, what, where, how, when and why" of lean construction.

Source: Rybkowski 2012

In 2013 Rybkowskiet al. presented "On the Back of a Cocktail Napkin: An Exploration on Graphic Definitions of Lean Construction”. Their conclusion is shown in Figure 1.

Two years later Leong et al (2015) sought an 'Operational Definition of Lean Construction Onsite'. The authors conclude "In order to [test the leanness of construction projects], we must first have a robust and defined methodology and operational measures of what lean construction is, i.e. a standard measure of lean application (leanness)."'One of the authors told me that a tool to test the leanness of construction projects exists (and is valued by users) but there is no robust operational definition of lean construction per se.

The latest P2SL glossary equates lean construction and lean project delivery: "Lean Construction, Lean Project Delivery = Application of lean thinking to the designing and making (or delivery at large) of capital projects (or projects in general).

The LCI website, quoted by Gao \& Low 2014, offers "A production managementbased approach to project delivery ...[that] is particularly useful on complex, uncertain and quick projects."

The Integrated Project Delivery Collaborative website includes "a production management based approach to project delivery - a new way to design and build capital facilities. http://ipdfl.net/processes/ipd-lean-construction/ 19 Nov. 17 


\section{METHOD}

From time to time we all have to answer this question: "What is lean construction?" I wanted to know the favourite answers used by members of this community. So, using a virtually identical request, I asked the community via a number of overlapping channels:

- LinkedIn article. That article was "reposted" 3 times by others.

- Posting a 'discussion' on 2 lean construction groups on LinkedIn

- Email to the IGLC yahoo group, copied to selected individuals.

- I also took definitions from the first 20 results from Googling the question.

Altogether, within a period of six weeks I received 42unique 'definitions' via email or via comments on LinkedIn from 39 authors - yes, some people submitted 2 or more definitions. In addition, I have considered 26 definitions retrieved via Google search on the term 'what is lean construction?' This is not a systematic review of the literature.

\section{WHAT IS LEAN?}

According to the Lean Enterprise Institute http://www.lean.org/WhatisLean (14Apr16) lean $=$ Creating more value for customers with fewer resources.

Chauncey Bell suggests that lean is not definable. He put his thoughts on the subject into the Forward he wrote for Hal Macomber's recent book The Pocket Sensei:

"Most of those who employ this word [lean] today think that they are pointing intelligibly to coherent, valuable practices, tools, and methods - whether originally derived from the Toyota experiences or not - that will move people and organizations toward some cohesive path of improved action. However, the word lean itself does not reliably indicate any particularly organized direction of thinking for improving a difficult situation, despite what we might guess from reflecting on old jargon such as lean and mean. There is no stable method or approach called lean.... .... Unfortunately, what the word lean points to today is little more than what the word modern indicates. (Macomber 2017, xiv)"

In an email Chauncey wrote:

"I am a serious critic of the current enactment of ... lean .... It misses the mark for many reasons. .... ... it is a slogan used by all manner of people, some of whom are serious people, and too many are shallow wannabe's looking for the latest fad.

"For me, the lack of a heart of the matter is not a bad thing.

"Lean as we watch it today, is an American tradition built by consultants and writers attempting to say sexy things that come out of the wake of what Ohno and colleagues did at Toyota. Their observations were idiosyncratic, fragmented, without ANY attention to the heart of the matter which has to do with cultural traditions and language. The discourse failed at all of the big 3 automotive companies, has produced a collection of important practices in manufacturing in the West, and is busy failing in construction in the West. 
"I think that we'll all be better off if what we call lean is replaced, soon, by some new exploration. [my emphasis]. Chauncey Bell, email

In an email unconnected with this study Koskela wrote something similar:

there is no robust explanation for lean. This makes it easier to reject lean. (17Nov17)

\section{SURVEY RESPONSES: WHAT IS LEAN CONSTRUCTION?}

Sven Bertelsen emailed (Sven's emphasis):This seemingly simple four-word question is hard to answer, not least because our understanding has changed over the years and is still changing. .... The most important thing is that Lean Construction is based on theories about the project's nature. Originally the Transformation-Flow-Value theory [Koskela 2000], .... In practical terms, this implies that the client and his satisfaction is the guiding light and the schedule is more important than the budget in the day to day management. .... A later theory ... is complexity theory ... This makes Lean Construction accept and deal with the construction projects' natural complexity and dynamics, and treat it as an adaptive system existing on the edge of chaos. ... Finally, Lean Construction stimulates and improves cooperation between trades in the daily operations, and thereby further stimulates the learning process. [Thus] Lean Construction is:

1. "A new way of managing projects based on two theories, The Value-FlowOperations theory that puts schedule \& logistics before budget \& work, and chaos theory that introduces pull logistics through Last Planner. Sven Bertelsen, email

2. "A management principle that stimulates continuous learning and improvement and supports cooperation.

Sven Bertelsen, email

Sven is not the only person with 2 or more offerings. John Rooke offered three:

1. lean = the design of slack. (Slack being the amount of redundancy that a complex system requires in order to sustain itself. Too little slack leads to breakdown, too much is waste. The problem, then, is to distinguish between waste and necessary slack. This is coherent with a Flow perspective) John Rooke, email 2. principally the management of learning and commitment John Rooke, email 3. (favourite) the elimination of waste, particularly waste of time. John Rooke, email "A collaborative, proactive, transparent, and involving environment, focusing on an optimal production flow for the end product, systematically and visually using combined work and plan processes, cross-functionally keeping the bigger picture in mind."

Hans Thomas Holm, Linkedin

" a way of thinking to create more value for the customer with fewer resources; focus on flow, continuous improvement and value for the customer.

Anon, email

"exactly what the customer wants, exactly when they want it, with nothing in store.

Kristen Parish, email

Kristen Parish added:Clearly, you can't perfectly do this in construction (hence, strategic buffers), but I tell students and professionals alike that we should strive for this. 
"synchronised harmony

Christine Pasquire, email

Christine Pasquire explains: this I believe covers every aspect of lean construction when you unpick the meaning of each word and their combined use. There is no way prevailing practice can make any claim under either word ....'

Shang Gaooffered both the Koskelaet al 2002 and the above LCI definition commenting:both acknowledge LC is a production system for projects. The first one also highlighted three goals of a production system - deliver project, minimize waste and maximize value. The second one points out what kind of projects are suitable for $L C$.

All the definitions received and others found on the web (together withan analysis of the concepts included in or alluded to in each of the definitions) are in an appendix published elsewhere [on Researchgate.net at https://bit.ly/2KYPDsT]. The analysis of the 68definitions submitted is summarised in Table 1:

Table 1: summary of definition analysis - most frequently mentioned concepts + \#

\begin{tabular}{|lc|lc|}
\hline Concept & $\#$ & Concept & $\#$ \\
\hline Value, customer need & 35 & Flow & 8 \\
\hline Waste reduction & 17 & Thinking, lean thinking & 8 \\
\hline Collaboration, team work & 16 & Lean manufacturing, TPS & 6 \\
\hline Delivery, outcome & 15 & Lean principles & 5 \\
\hline Production Management & 14 & LPS or ref to key features of LPS & 5 \\
\hline Less input, resources required & 13 & Reliable & 5 \\
\hline Continual/continuous improvement & 11 & Faster and other refs to speed, time & 5 \\
\hline Process or system & 10 & Efficiency & 4 \\
\hline
\end{tabular}

Other concepts identified in the content analysis were: new (4), whole process (4), operational strategy (3), action (2), commitments (2), learning (2), philosophy (2), respect for people (2), TFV (2), tools, techniques (2), trust (2) - 7 others were mentioned once.

Should the lean construction community be worried that there is so little agreement?

\section{THE PURPOSE OF LEAN \&LEAN CONSTRUCTION}

Perhaps the easiest way to think about lean is in terms of its purpose. What we now know as lean was developed to enable Toyota to shorten the time between making a vehicle and being paid for it.

An early statement of IGLC's purpose was "to better meet customer demands and dramatically improve the AEC process as well as product. To achieve this, we are developing new principles and methods for product development and production management specifically tailored to the AEC industry, but akin to those defining lean production that proved to be so successful in manufacturing." http://cic.vtt.fi/lean/index.htm 12jun05

Ebbs 2017 wrote "The purpose of Lean is to provide every customer's value in the most efficient and effective manner possible." Like the purpose of lean suggested above 
there is no end, no destination for this purpose — it is, in Womack and Jones' words, a pursuit of perfection and that pursuit can have no end. But note: this too fails the Howell criterion.

Stafford Beer was fond of asserting that the purpose of a system is best assessed by studyingwhat it does (e.g. "a system is what a system does" (e.g. 2003)

Sacks et al (2017) describe the evolution of lean construction and what it does:

Lean construction can be seen as a progression not simply from craft and industrialized construction, but also from mass construction. Figure [2below]shows Lean Construction as derived from the three other classifications (craft, industrialized and mass construction). It inherits concepts from all three, as well as from Lean production.

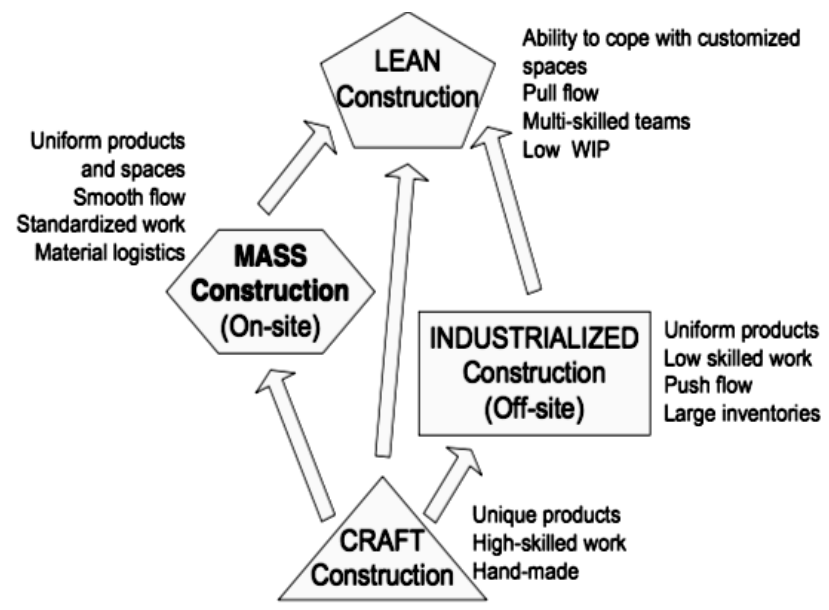

Figure 2: Evolution of construction production systems. Sacks et al 2017

\section{DISCUSSION}

Rybkowski et al (2013) report that when ZofiaRybkowski asked Greg Howell why the question "What is Lean Construction?" never goes away, he responded: "Is-ness is the problem for me. This is a computer, this is door. ...II surely would be better if we dropped the term lean....." (personal communication 2010) [my emphasis].

A number of respondents suggested that their definition depends on who is asking, or on the context. Rybkowski et al (2013) report that Alan Mossmantold one of the authors: "If someone asks 'What is lean construction?' I start by trying to find out why they want to know and what they already know. Then I have some ideas about how to respond. I feel that you are making a problem where none exists. Live with the ambiguity and help your students to do that too" (personal communication 2010).

Perhaps this explains why Iris Tommelein, custodian of the LCI Glossary entry above, wrote (2018) "Lean construction is systems thinking, respecting people, pursuing continuous improvement, and so much more." 


\section{CONCLUSION}

This brief study has revealed the diversity of views about the nature, scope and meaning of lean construction.

My own conclusion from this small study is that "lean" is a practical collection of theories, principles, axioms, techniques and ways of thinking that together and severally can help individuals and teams improve the processes and systems within which they work. I don't believe that this meets the Howell criterion, nor is it an operational definition.

Until we have an alternative to "lean construction" there is plenty of opportunity for further work in this area. The quick and dirty content analysis (summarised in Table 1) might be reviewed and a more systematic collection of published definitions be made.

In the meantime, I wonder if it would be more helpful to focus on defining the purpose of the system that we call 'lean construction'.

\section{ACKNOWLEDGEMENTS}

I am grateful to all who responded to my question - those who wanted to be, are named with their contribution.

\section{REFERENCES}

Austin, Robert B (2016)Successful delivery of flash track projects. $\mathrm{PhD}$, Georgia Tech Ballard, G. (2012) 'Should Project Budgets Be Based on Worth or Cost?' In: Tommelein, ID \& Pasquire, CL,20th Ann. Conf. of the Int'l Gp for Lean Constr'n. San Diego, USA

Beer, Stafford (2003) Diagnozing the Sytsem for Organisations, Chichester, UK, Wiley.

Dauber, V. F. (2003). Measuring and minimising waste in construction by applying lean thinking. PhD Thesis. University of Dundee, Dundee.

Diekmann, James E., Mark Krewedl, Joshua Balonick, Travis Stewart, \& Spencer Won (2004)Application of Lean Manufacturing Principles to constructionCII Report 191

Deming, W Edwards (1994) The New Economics (2e). MIT Press

Ebbs, Paul (2017) The Last Planner ${ }^{\circledR}$ System of Production Planning \& Control: The Foundation for Lean Project Delivery MPhil Thesis, DIT

Gao, S. and Low, S. P., (2014) The Toyota Way model: An alternative framework for lean construction. Total Quality Management and Business Excellence, 25(5-6), pp.664-82.

Green, SD(2010)Making Sense of Construction Improvement. Chichester, UK: Wiley

Green, SD\&SC May (2005) Lean construction- arenas of enactment models of diffusion and the meaning of 'leanness' Building Research \& Information (2005) 33(6), 498511

Howell, Gregory A (1999) "What is Lean construction - 1999."In: Proc. 9th Ann. Conf. of the Int'l Group for Lean Construction,

Inokuma, Akira(2017) The Present State of Lean Construction in Japan and a Better Way Forward. Lean Construction Bloghttp://leanconstructionblog.com/The-present-stateof-Lean-Construction-in-Japan.html 4 Jan 17 
Koskela, Lauri (2000) An Exploration towards a Production Theory and its Application to Construction. PhD Thesis, VTT, Finland

Koskela, L., Howell, G., Ballard, G., \& Tommelein, I. (2002). "The foundations of lean construction." In R. Best, \& G. de Valence, eds. 2010 Design and Construction: Building in Value, Butterworth-Heinemann, Elsevier, Oxford, UK.

Leong, M.S., Ward, S. \& Koskela, L. (2015) 'Towards an Operational Definition of Lean Construction Onsite ' In Seppänen, O., González, V.A. \& Arroyo, P., 23rd Annual Conference of the International Group for Lean Construction. Perth, Australia, 29-31 Jul 2015. pp 507-516

Macomber, Hal (2017)The Pocket Sensei - Volume 1 - Special Edition: Mastering Lean Leadership with 40 KatasLCI \&CreateSpace ISBN-13: 978-1976554667

Mossman, Alan(2012) Book Review- Green 2010 Making Sense of Construction Improvement Construction Research \& Innovation CRI 3(1) 20-23

O'Neill, Dan (2016) Understanding Lean and Lean Construction in Ireland. Irish Building Magazine https://www.irishbuildingmagazine.ie/2016/04/27/understandinglean-and-lean-construction-in-ireland/ 4Jan17

Pekuri, Aki, MailaHerrala, Aki Aapaoja\&HarriHaapasalo(2012) Applying Lean in Construction - Cornerstones for Implementation IGLC

Pettersen, J. (2009)Definingleanproduction:some conceptualandpracticalissues.TQM Journal 21(2), 127-142

Rybkowski, Z. K., Abdelhamid, T. S. and Forbes, L. H., 2013. On the back of a cocktail napkin: An exploration of graphic definitions of lean construction. In: Proc. 21st Ann. Conf. of the Int'l Group for Lean Construction, Fortaleza, Brazil

Sacks, Rafael, Samuel Korb, Ronen Barak (2017)Building Lean, Building BIM: Improving Construction the Tidhar Way. Routledge.

Sayer, N. and Anderson, J. A. J. (2012). Status of lean in the construction industry. Rider LevettBucknell, 17 pp.

Seed, Bill (ed) (2010)Transforming Design \& Construction: a framework for change. Lean Construction Institute, Arlington VA

Stevens, M., (2014) Increasing adoption of lean construction by contractors. In: Proc.22nd Ann. Conf. of the Int'l Group for Lean Construction, Oslo, Norway,

Tommelein, Iris (2018)Discussion of "Toward Error Management in Construction: Moving beyond a Zero Vision" by Peter E.D. Love \& Jim Smith. J. Constr. Eng. Manage., 144(1) 